\title{
ACERCAMIENTO A LA MUERTE DESDE LA ANTESALA DE LA MUERTE MISMA: LAS ULTIMIDADES
}

\author{
Soledad GÓMEZ NAVARRO \\ Universidad de Córdoba
}

\begin{abstract}
Resumen
De todos los posibles gestos cercanos a la muerte, esta aportación analiza el de la agonía por ser el menos tratado por las fuentes al uso; constituir buena representación de la privacidad/publicidad que es la muerte preindustrial; y aportar la dimensión sociocultural complementaria a la estricta y asépticamente demográfica. Siempre desde la integración contrastada de los textos, utiliza para ello documentación parroquial, impresa -tratadistas, moralistas, creaciones literarias-, examen minucioso del mensaje testamentario sobre todo. Atiende así a su esencia -trance acompañado-, desarrollo-trance pesaroso- y desenlace -trance fatal-, las tres partes en que se estructura.
\end{abstract}

\begin{abstract}
Of all the possible expressions of death, this paper analyzes that of agony. As the expression of death which is least studied in the sources, agony constitutes a faithful representation of the private/public character of death in the pre-industrial age adding a sociocultural facet to the strict, aseptic demographic dimension. A comparative study of text -parochial and published documents such as essays, moral treatises and literary sources is undertaken. Most importantly, an in-depth examination of testamentary documents is carried out. The paper is structured into three parts: the essence of agony-moments of accompainment-, its evolution -moments of sorrow, and its final outcome- the moment of death-.
\end{abstract}

Recibidos los tres últimos santos sacramentos, dictado testamento y naturalmente acelerado el mal, alguien -en esto no hay sexos-, en su cama y en su casa, que era lo esperable y deseable para empezar a vivir la llegada de una buena muerte', se apresta a pisar, exhalando el último suspiro, la última fase de la vida: la agonía. La

1. Gittings, Cl., Death, burial and the individual in early modern England, Londres, 1984, p. 103. Apud.: González. Cruz, D., Religiosidad y..., p. 191, n. 1. 
agonía es la luz roja que avisa de que los enfermos ya están en situación de no poderlos desamparar y de que se ha entrado, por tanto, en hora crítica, y estado que se muestra en absurdos e inexplicables deseos de comer o bien todo lo contrario -inopinada y absoluta pérdida de apetito-, debilidad y/o alteración de pulso, sudores en frente, cara y pecho, amoratamiento de mejillas, labios y dedos, enfriamiento de pies, manos y nariz, inquietud, aceleración, dificultad para arrojar y respirar bien, excesiva locuacidad, desvaríos, furias repentinas, excesivo insomnio, inusitada sed, intranquilidad, ojos vidriados, convulsiones, incontrolado interés por levantarse e incluso escapar, súbitas inflamaciones y punzantes y fuertes dolores, según distintas enfermedades; en tocamiento de ropa, lágrimas involuntarias, solicitud de comer estando fatigado e inapetente, $y$ petición de ser mudado de una parte a otra, en males o enfermedades graves; y, en fin, en fatiga continua de respiración, debilidad suma de pulso o celeridad con intercadencias, y continuada vigilia hasta el punto de que, si se desea dormir algún rato, no se puede cerrar los ojos, quedándose con la vista fija y aquéllos empañados, que son señales universales de muerte ${ }^{2}$.

De todos los posibles gestos cercanos a la muerte, rico ceremonial que se desarrolla en sus prolegómenos, hemos escogido la agonía -lo último de lo último, de ahí el título de la colaboración- por ser el menos conocido y/o tratado por las fuentes al uso; constituir una buena representación de lo que la muerte del Antiguo Régimen es y significa; y aportar de esta forma una dimensión sociocultural, bastante complementaria a nuestro parecer, a la estricta y asépticamente demográfica.

Nos servimos para ello, y partiendo de nuestras propias investigaciones, de documentación manuscrita -notarial y parroquial fundamentalmente, y la primera sobre todo bien repartida sexual, social, cronológica y espacialmente- e impresa -tratadistas, canonistas, creaciones literarias-, y desde el tamiz de una lectura atenta, integrada e integradora y contrastada de los textos. Coincidiendo con las tres partes en que se estructura esta aportación, nos preguntamos qué era y en qué consistía; cómo se abordaba y sentía; y cómo terminaba.

\section{TRANCE ACOMPAÑADO}

En expresiones de los mismos protagonistas, la agonía es hora terrible, terrible y olvidada, peligrosa, incierta, formidable y única porque «todos los instantes son pocos para pensar el grande y único negocio de la salvación» ${ }^{3}$, última ${ }^{4}$, combativa y combatida, postrimera, sufrida, difícil, «centrada a la eternidad ${ }^{5} \mathrm{y}$ decisiva ${ }^{6}$.

2. Fernández. A., Instrucción de.., $2^{2}$ parte, ff. 3-7. Venegas, A., Agonía del.., p. 37. Mach, J., Tesoro del..., 2, pp. 449-450.

3. Archivo de Protocolos Notariales de Córdoba-APNCO, en lo sucesivo (APNMO, si es Montilla; APNFO, si Fuente Obejuna), cuyos fondos hoy insertos en el Archivo Histórico Provincial; primer dígito, oficio; segundo, protocolo; año entre paréntesis; últimos dígitos, folios-, 12, p. 376 (1830), $1.373-$ 1.379 v., f 1.373 v.: Testamento de D. Juan Ruiz y Huertas.

4. D. Juan Rafael Paniagua y González [APNCO, 5, p. 183 (1830), 423-426v.] solicitaba de sus albaceas la curiosa petición de que se apoderaran de sus casas y llaves cuando entrara en la agonía y, por tanto, «ya no se dude de que estoy en el último periodo de la vida», $\mathrm{f}^{\circ} 424 \mathrm{v}$; o en el «trance último de mi vid $t$ », como indicaba Da Juana Josefa de Aguilar: APNMO, 6, p. 1.109 (1750), 160-165r., fo 160v.

5. APNCO, 4, p. 216 (1770), 244-257r., fo 245r.: Testamento de D. Juan de Carmona Moreno.

6. Lacordaire, E. E., Sermones predicados en..., 1, pp. 81-2. 
Es oportunidad ideal para disponerse a vivir «una buena muerte» ${ }^{7}$ y asimismo excelente expresión del antagónico doble sentido de la muerte del Antiguo Régimen, a la par, publicidad y privacidad, colectividad e individualidad, pues se muere en comunidad $^{*}$, en familia", pero también, y sobre todo, se muere solo, auténticamente solo ${ }^{10}$.

Es igualmente lucha, combate, «lance» ${ }^{11}$, paso -por su misma etimológica significación- «para la felicidad y vida eterna» ${ }^{12}$, puerta angosta y puente estrecho ${ }^{13}$, y receptáculo de todo, desde la vigilancia, el sufrimiento y la ayuda, hasta la desesperación y, por supuesto, el acabamiento y la muerte.

Pero es ante todo el tránsito de la vida a la muerte que el moribundo no salva o libra solo, desamparado, sino contando con el apoyo de asistencias personales, espirituales y materiales, porque, desde que se inicia -ya empieza a actuar la solidaridad colectiva-, en su habitación se ve rodeado, está acompañado.

En primer lugar, de caritativos amigos que se han acercado para animar y confortar, con su presencia, a quien más en esos momentos lo necesita.

Por supuesto, están los familiares directos, padres, esposa, hijos, que, con bastante seguridad desde el testamento y diversos puestos -albaceas, legatarios, comisarios, por ejemplo-, prolongan su presencia en la sala mortuoria, si bien se solicita la salida de la segunda y los últimos, especialmente si han sido adulterinos, antes de que el «passamiento» llegue a su clímax o paroxismo para evitar que aumenten las tentaciones y pasiones de la agonía o que su sola presencia robe intensidad a la debida dedicación espiritual o reste efectividad al conveniente desprendimiento que el espíritu debe realizar de todo lo afectivo y terreno ${ }^{14}$.

Igualmente aparecen los cofrades, por lo general por imperativos, aunque de buen y generoso grado, de sus mismos estatutos ${ }^{15}$.

7. Fernández. A., Instrucción de..., $2^{\mathrm{a}}$ parte, $\mathrm{f}^{\mathrm{p}} 7$.

8. Royer de Cardinal, S., Morir en..., p. 119.

9. La «muerte familiar» de J. et R. Nicolas, La vie quotidienne en... 125-9.

10. Royer de Cardinal, S., Ibid. Hasta el punto de que aun después de muerto, y por supuesto en la agonía, es la muerte vivida que uno hizo a través del discurso testamentario implicado, el desarrollo de la disposición y preparación que cada quien quiso de «su muerte», de su propia muerte: Hildebrand, D. v.. Sobre la.., p. 56.

11. APNMO, 1, p. 133 (1730), s. f.: Testamento de D. Juan Francisco de Cassasola Dávila y Castroviejo.

12. APNCO, 25, p. 108 (1690), 246-249v., f 246v.: Testamento de D Juana Fernández de Córdoba Ponce de León.

13. Eliade, M., Lo sagrado y lo..., pp. 152-4, sobre la visión de San Pablo. Porque, como la muerte a la que precede, prefigurada en la caída de la Ciudad Santa de la que se sirven profeta y apóstol para explicar el sentido cristiano del fin, también la agonía es necesario tiempo de encogimiento o reducción, ya que «por las fatigas de su alma, verá luz» (Isáas, 53, 111: Biblia de..., edic. 1972, p. 1.322), apuro o aprieto que no puede esquivarse uporque vendrán dias sobre tí, en que tus enemigos te rodearán de empalizadas, te cercarán y te apretarán por todas partes» (Lucas, 19, 41-43: Ibíd., p. 1.777).

14. Venegas. A., Agonía del..., pp. 48-51.

15. Fue de los que se sirvió D. Pedro Antonio de Rivera para encargar a sus albaceas que, como indigno discípulo de la Escuela de Cristo, cuando cayese en cama de cualquier enfermedad, lo notificasen al Padre de Obediencia que a la sazón fuera de dicha congregación para que lo participase a sus hermanos «y todos se sirvan por su gran caridad de ayudarme con sus oraciones y sufragios, y en la misma forma vayan dando noticia, si me estrechare en el accidente con proximidad a fallecer para que dicha Santa Escuela cumente sus sufragios y oraciones, como acostumbra y en la propia forma en la ocasión de mi muerte, como asi lo espero de su gran caridad»: APNCO, 11, p. 93 (1720), 160-162v., $f^{\circ} 162 \mathrm{r}$., subrayado nuestro. 
También se rodea de santos, especialmente San José, «por estarles concedidos estos dones por Nuestro Señor Jesucristo en la hora de su tránsito para que los usara con sus devotos y pida al Espíritu Santo por su salvación» ${ }^{16}$, y también de Nuestra Señora, «la Reina soberana de los ángeles y su favor por medio de aquel Libro soberano que compuso San Buenaventura para invocar su asistencia en la hora de la muerte» ${ }^{17}$, a todos los cuales se les pide amparo, mediación, protección, auxilio y ayuda «para poder superar felizmente los grandes peligros de la última hora de mi vida» ${ }^{18}$.

$\mathrm{Y}$, sobre todo, se acompaña del ministro, del sacerdote ${ }^{19}$, junto con el moribundo, el otro, y casi imprescindible, gran protagonista, no sólo porque es el único que ha podido realizar la previa acción de la administración sacramental, sigue alentando al constante arrepentimiento, y debe continuar animando al recogimiento y entrega hasta el final, sino también, y especialmente, porque morir y acabar solo o abandonado, sin ayuda eclesiástica, es muy peligroso ${ }^{20}$. Sólo en caso de que por cualquier circunstancia aquélla faltara, podía recurrirse para asistir al moribundo, para seguir desempeñando esa función, a cuyo fin abundaban tratados para ayudar a bien morir, a una persona piadosa: es lo que deseó que se hiciera, previendo que pudiera ocurrir, adelantando la eventualidad, $\mathrm{D}^{\mathrm{a}}$ Marina Pérez Prieto y Gálvez, quien legaba una basquiña y un manto, «los más inferiores que dejara por mi fallecimiento, a la persona que me asistiera en mi última enfermedad ${ }^{21}$.

Por último, la agonía también necesita de pertrechos, protecciones, señales: rosarios; reliquias; imágenes sagradas; crucifijo que se coloca entre las manos ${ }^{22}$; bulas, especialmente de difuntos que se han comprado para tal fin o que se tienen y que, como talismán, se ponen junto al moribundo ${ }^{23}$; los mismos sacramentos; el repique

16. APNMO, 1, p. 132 (1720), 126-144v., f 127r.: Testamento de Da Antonia de Córdoba y Zamora. Por eso es el patrono de la «buena muerte»: Garzón, F. de P., Devocionario en honol- del..., pp. 99, 104-6, 123-5. Vovelle, M., Piété baroque et..., p. 167.

17. APNCO, 19, p. 172 (1740), 159-160v., f 159r.: Testamento de D. Juan de la Cruz y Bilchez. Acerca de las asistencias espirituales, abogados que acompañan al moribundo, que aparecen al lado del justo a la hora de la muerte, Ligorio, A. $\mathrm{M}^{\mathrm{a}}$ de, Preparación para la..., p. 125.

18. APNCO, 4, p. 145 (1710), 495-499r., fo 496r.: Testamento de D. Gabriel López Valero. O para que «consiga salir de esta miserable vida en gracia, y por medio de ésta, logre mi alma verle cara a cara y gozar de su visión beatifica por toda una eternidad [...]. para que multiplicadas las intercesiones consiga yo salir de este mundo en paz y el eterno descanso de mi alma»: APNFO, p. 439 (1760), 20$28 v ., f^{\circ} 21$ r.: Testamento de Francisco de Morales Quebrajo.

19. APNCO, 24, p. 99 (1820), 7-14v.: Testamento de D. Francisco Javier de Lén y Luque: mandaba 20 reales de vellón -r.v., en lo sucesivo- al sacerdote que «me auxilie a bien morir; en reconocimiento del trabajo y de la incomodidad que habrá de poner en esta obra de piedad y caridad», $\mathrm{f}^{\circ} 8 \mathrm{v}$. APNMO, 5, p. 934 (1820), 24-27v.: Testamento de Diego Pérez Alcaide: legaba 100 r.v. al sacerdote que le asistiera hasta la última hora para que con ellos le dijera una misa rezada por su alma e intención. APNCO, 12, p. 324 (1810), 1.005-1.107r.: Inventario de los bienes dejados por D. Fernando Pérez Valdivia: se abonaron $60 \mathrm{r.v}$, a un fraile capuchino por haber asistido al difunto a ayudarle a bien morir como pidió en su testamento, acompañandole varios días hasta que expiró.

20. Montañés, J., Espejo de bien..., p. 369.

21. APNCO, 12, p. 206 (1760), 89-90v., fo 90v.: Testamento de la dicha.

22. Bosch de Centellas y Cardona, B., Prácticas de visitar los..., pp. 47-53.

23. APNCO, 23, p. 287 (1820), 160-257r.: Inventario de los bienes dejados por D. José Ma Roldán y Bàquero. Acerca de los beneficios que por las indulgencias reportan y de su conveniencia para los fieles por ser medios conducentes a lograr la buena muerte que desean, Ligorio, A. Ma de, Preparación para la..., pp. 367-8. Bosch de Centellas y Cardona, B., Op. cit., pp. 34-5. Mach, J., Tesoro del.., 2, p. 450. 
de campanas ${ }^{24}$, el aviso -no en vano son «el estertor del moribundo» ${ }^{25}$ - a la comunidad de la ya inminente muerte de uno de sus miembros para que se uniera al esfuerzo que en aquel momento aquél hacía, a sus oraciones, y lograra la salvación de su alma; agua bendita con que, para alejar demonios y tentaciones, obtener perdón de pecados veniales, ahuyentar el temor a la ya muy próxima muerte y apagar algunas llamas del purgatorio, se rocía no sólo la persona del agonizante y su cama, invocando el nombre de Jesús, sino también toda la estancia ${ }^{26}$; y, sobre todo, la mortaja, que se coloca normalmente tras morir, pero también puede hacerse previamente - «antes de que yo fallezca se me pondrá y vestirá el hábito de San Francisco para que expire con él» ${ }^{27}$; «al tiempo que yo quiera expirar, se me dé el hábito de Nuestra Señora del Carmen» ${ }^{2 *}$; «antes que yo fallezca se ponga sobre mi cuerpo hábito de los religiosos de la Santísima Trinidad de Redentores descalzos» ${ }^{20}-$, ya que, por sus también muy idóneos beneficios para el trance al producir indulgencias, gracias y perdones en pródiga abundancia, es uno de los mejores escudos disponibles a tal fin de que el mismo moribundo puede dotarse para auxiliarse y fortalecerse aún más ante y en el duro, y ya muy inminente, combate ${ }^{30}$.

\section{TRANCE PESAROSO}

La agonía no es tampoco fácil ni pacífico combate, sino pesado y doloroso, como el del mismo Cristo, quien, el primero, sufrió también su propia agonía ${ }^{31}$, porque, ámbito de contienda como sabemos -es lo que el término significa-, es lucha y pelea tanto entre el alma y el cuerpo, que se separan en el momento de la muerte y ya para vida eterna o muerte eterna - por eso es aquélla lid transitoria-, como entre las fuerzas del bien y del mal, que se enfrentan en el propio cuerpo del enfermo al que toman como deseado e indefenso campo de batalla ${ }^{32}$.

Es, en efecto, el tiempo, tan sabido y reconocido, del maligno, que ataca para «perder el alma» ${ }^{3.3}$ y perturbar la mente, apartándola de las cosas espirituales «y de la estrecha cuenta que se espera dar a la Divina Majestad» ${ }^{34}$, y conseguir, o por lo me-

24. APNCO, 19, p. 205 (1820), 121-186r.: Inventario prevenido a los bienes que por su muerte dejó D. José Posadas: por el tañido de las que, en su agonía y después, le tocaron, se pagaron 15 r.v.

25. El Costumbrismo..., aportación de Larra: «El día de difuntos de 1836. Fígaro en el cementerio», p. 123.

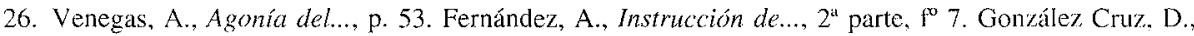
Religiosidad y..., p. 199.

27. APNCO, 1, p. 142 (1730), 114-117v., fo 115r.: Testamento del Licenciado D. Juan Antonio de Ayora, subrayado nuestro.

28. APNCO, 30, p. 318 (1690), 577-579v, fo 577v.: Testamento de $\mathrm{D}^{\mathrm{a}} \mathrm{M}^{\mathrm{a}}$ Manuela de Melgar.

29. APNCO, 6, p. 183 (1760), 125-132r., f 126r.: Testamento de D. Gonzalo Antonio Serrano.

30. Entre muchos otros que recogen estos beneficios, APNCO, 24, p. 70 (1730), 738-640v.: Testamento de D. Fernando Benito Mohedano. Por recoger asimismo esta práctica de «un hábito para morir», Martinez Gil, F., Muerte y..., pp. 382-5, en general 359-395.

31. Mateo, 26, 36-46. Marcos, 14, 32-42. Lucas, 22, 39-46: Biblia de..., edic. 1972, pp. 1698, 1730-1, 1.784 , respectivamente.

32. Venegas, A., Agonía del..., pp. 54-5.

33. APNCO, 4, p. 145 (1710), 14-23v, f $\mathrm{f}^{\circ}$ 15r.: Testamento de D. Gabriel de Benavente y Muñoz.

34. APNCO, 17,70 (1760), 401-418r., f 401v.: Testamento de D. Francisco Ruiz Camacho y Almagro. 
nos intentar, contradicciones, retractaciones o desviaciones de la fe confesada. El preámbulo testamentario lo recoge, con inusitada variedad, prolijidad y riqueza, en él:

«Y protesto de lo que en contrario de esto dijere si el demonio, enemigo común, valiéndose de la fragilidad o turbación de mis sentidos, lo dijera» ${ }^{3.5}$.

«Y lo mismo imploro de San José para que en aquella hora me asista y me libre del demonio y sus tentaciones y de morir en pecado» ${ }^{36}$.

«Con todo lo demás que tiene, cree y confiesa Nuestra Santa Madre Iglesia Católica Apostólica Romana, bajo cuya fe y creencia he protestado vivir y morir como católico fiel cristiano sin que las acechanzas del enemigo común del género humano no sean bastantes a apartarme de ello» ${ }^{37}$.

«Ordeno mi testamento desamparándome de los bienes temporales para que queden aplicados a mis obras y limpiar la conciencia para que por esta razón el enemigo no me combata en aquella tremenda hora y último lance de la vida» ${ }^{38}$.

$\ll Y$ creo en todos los misterios que nos manda Nuestra Santa Madre Iglesia Católica Apostólica Romana, con cuya fe y creencia he vivido y protesto vivir y morir, con detestación de todo lo que pudiere ser en contrario a la Universal Iglesia de Roma, y si ocupado de algún accidente, enfermedad o sugestión del enemigo común por obra o por palabra, señal o en otra forma alguna pareciere cosa en contrario, desde luego la doy y declaro por no dicha ni hecha, y de todo corazón la detesto y aborrezco como contraria mi voluntad y verdadero sentido ${ }^{34}$.

« $Y$ protesto vivir y morir como católico fiel cristiano, y detesto y anatemizo todas aquellas herejias que tiene anatemizadas y detestadas la fe, los sagrados cánones y concilios, siguiendo el estandarte de la fe santísima y la ley de Jesucristo Crucificado Redentor Nuestro, en que vivo y quiero vivir, de tal suerte que (si Dios no lo permita), por fragilidad humana, por sujeción del demonio o habiendo perdido el juicio contra esta sagrada verdad y fe que profeso dijere, hiciere o pensare alguna cosa, desde ahora para entonces en virtud de esta cláusula la revoco, anulo y es mi voluntad no se tenga por dicho, ni hecho ni pensado» ${ }^{41}$.

$\mathrm{O}$ en el «bajo cuya fe y creencia he protestado vivir y morir como católica fiel cristiana y si acaso por delirio, sugestión del común enemigo oflaqueza de la debilidad y miseria de lo deleznable y frágil de mi vil naturaleza, algo pensare, dijere, o imaginare en contra de esta protestación, desde luego lo abjuro, detesto y protesto ser contra mi voluntad, y por el mismo hecho ratifico y me afirmo en la referida confesión de todo lo expresado, contra que no quiero valga lo que en contrario dijere o pensare» ${ }^{4 !}$.

35. APNCO, 1, p. 142 (1730), 114-117v., $1^{\circ} 115 \mathrm{r}$.: Testamento del Licenciado D. Juan Antonio de Ayora. En todo caso, subrayado nuestro.

36. APNMO, 1. p. 133 (1730), s. f:: Testamento de D. Juan Francisco de Cassasola Dávila y Castroviejo.

37. APNCO, 20, p. 62 (1720), 111-124r., fo 112r.: Testamento de D. Gabriel de Corral y de los Ríos.

38. APNMO, 1, p. 132 (1720), 91-94v., f 91r.: Testamento del Licenciado D. Fernando de Inestrosa y Esquivel.

39. APNCO, 29, p. 89 (1690), 195-201v., f 195v.: Testamento de D. Francisco de la Peña Tercero.

40. APNCO, 40, p. 34 (1710), 644-649v., f 645r.: Testamento de D. Fernando Antonio González Durán y Luna.

41. APNCO, 11, p. 93 (1720), 368-371 v., fo 368v.: Testamento de $\mathrm{D}^{\mathrm{a}}$ Ana $\mathrm{M}^{\mathrm{a}}$ Camacho del Real. Sobre referencia y prevención al maligno en la agonía, hay quien ve en estas cláusulas tan «de sospechosa firmeza» reatos de un antiguo pasado protestante o, por lo menos, afecto durante algún tiempo a desviacionismos, pero también -nosotros por ejemplo- los estrictos y recios efectos del aún cercano Trento. 
Es el momento, por tanto, del enfrentamiento entre ángeles y demonios a la cabecera de la cama del agonizante ${ }^{42}$; del opuesto encuentro entre aquéllos y éstos, y los últimos, visibles o presentables a través de mil formas y visajes para enredar y desordenar al moribundo; de las tentaciones, pues, que sólo pretenden alterar, trastocar y confundir valores, implantando por mor del maligno «infidelidad por fe, desconsuelo por esperanza, malicia por caridad, ignorancia por prudencia, tiranía por justicia, temor por fortaleza y exceso por templanza» ${ }^{43}$; o, lo que es igual, fe y engaño por fortaleza, desesperación por confianza, impaciencia por paciencia, vanagloria por complacencia y soberbia, avaricia y apego a cosas mundanas por humildad y renuncia. Todo deriva de que la contienda se entabla entre el bien y el mal; entre el ángel que conforta y el demonio que perturba; entre éste, que sólo pretende perder el alma del moribundo, convenciéndolo de que ya ha logrado su salvación y que, por tanto, ya no necesita fijar los ojos en la ayuda y gracia de Nuestro Señor, y aquél, que busca hacerle ver justamente lo contrario, que lo conseguido hasta ahora no ha sido por méritos propios sino de Jesucristo y que, por consiguiente, tiene que seguir imitándolo ${ }^{44}$. Únicamente es aliviado o aligerado este tiempo, y finalmente casi siempre vencido, por el sacerdote que, en uso obviamente de sus propias atribuciones, desarrolla un febril seguimiento de la evolución del mismo espíritu del moribundo, seguimiento que no tiene tregua y que se redobla precisamente en los momentos terminales, en un ritmo que va «in crescendo»: preces; oraciones; jaculatorias; encomendaciones a Jesucristo, Virgen, santos, ángeles, arcángeles, toda la corte celestial; salmos -«Miserere mei», «De profundis», «Animae Christi»-; letanías; pláticas; lecturas y/o comentarios de libros sagrados o religiosos; protestaciones y actos de fe, esperanza y caridad; y, en fin, pequeños ejercicios de piedad -rezo de las divinas siete palabras; petición de

42. Epístola de San Pablo a los Efesios, 6, 10-20, Biblia de..., edic. 1972, pp. 1.967-8. Venegas, A., Agonía del..., pp. 143-4. Zorita, A., Catecismo del..., pp. 300-301. Cabe preguntarse ante ciertas lecturas si tendrá alguna responsabilidad en el visceral temor de los fieles a la muerte esa tendencia de algunos escritores o moralistas a presentarla, aun sin querer, como frontera que, por su naturaleza, proceder o modo de llegar, espanta.

43. APNCO, 42, p. 21 (1780), 54-60v., ff. 54r-v.: Testamento de D. Antonio Castillejo y Velasco, quien legó el mejor testimonio del trance de la agonía en mejor pasaje: «pidiéndonos vivamos alerta, esperándole de instante en instante, para que usando de nuestro talento, no hallarnos desprevenidos en aquella terrible lid en que el adversario esgrime con mayores esfuerzos las traidoras armas de su maliciosa milicia contra los fuetes homenajes -sic-en que se encastilla y defiende nuestra preciosa eterna alma, con el depravado e inicuo fin de abatirla; para lo que juntando su grey le pone el más asedio y riguroso sitio con tantas y tan varias especies, detentaciones, figuras y disfraces, como su maligna ciencia le prepara, ya influyendo, ya cambiando y simulando infidelidad por fe [...], entallandose en las pasiones humanas, influyéndoles a rebelión contra la razón y, cuando más no puede echando el último esfuerzo de su malicia, se presenta a la lid visible como diablo patente y meridiano, poderoso y principe del mundo, sin ningún embozo, embarazando el escudo de los defectos humanos (que hace patentes) provocando a la desesperación, vibrará con tanta furia el corvo acero de la obstinación, que a no esgrimir unidas las fuertes virtudes con valor, apoyando en el fuerte alcázar de donde dimanan, escudándose con el expugnable troquel de la pasión, sangre y muerte de Nuestro Campeón y Redentor Jesucristo sus superabundantes méritos, puesto el objeto en la soberana deidad sin idolo ni vanidad propia, y haciéndose cargo de que como con tanto nuevo pecado, aún tiene el alma capacidad de merecer, porque puede decir triunfante con el alférez de la milicia celestial quien como Dios en triunfo de vencimiento pudiera conseguir el adversario su funesto inicuo intento».

44. Montañés, J., Espejo de..., pp. 213-5, 310-2, 314, 316-7, 319 y 321-8 
perdón y verdadera contrición de haber pecado, búsqueda de elevados pensamientos..., sobre todo abandono de mundanidad y generosa entrega a Dios ${ }^{45}-$, iniciados y conducidos por el ministro y continuados por el combatiente, siempre vuelto a la Vida, Pasión y Muerte de Cristo, su espejo y ejemplo, y sólo dirigidos a su animación, perseverancia y fortalecimiento ${ }^{46}$.

\section{TRANCE FATAL}

Por desgracia, también la agonía, que no tiene espera y que se redobla precisa y justamente en los momentos terminales, está siempre llamada a un mismo, único, ineludible y definitivo destino culminando el proceso: con el postrer suspiro, ese instante último, frontera entre la vida y la muerte ${ }^{47} \mathrm{y}$ hecho presente, patente, en la impotencia con que le cuelgan al recién muerto cabeza, brazos y manos, palidez, enmarañado desorden de cabellos, hundimiento de sienes, abatimiento de orejas, profundidad de ojos en mirada espantosamente fija, depresión y flacidez de mejillas, afilamiento de nariz, contracción de boca, sequedad de lengua, rigidez y frialdad de cuerpo todo ${ }^{48}$, labios de color de plomo ${ }^{49}$; en la, pues, paralización completa y suma aniquilación ${ }^{50}$, muere, al fin, el fiel.

Ese momento infinito es también agente de tanto buena como mala muerte -para quien la sufre, la primera faz plácida, natural, apenas notada, como si, sin que se hubiese producido, aún la persona viviese ${ }^{51}$; la segunda, ajada, desastrada y descompuesta ${ }^{52}-$

45. Con el «me desapropio de todos los bienes de esta vida y es mi voluntad estar y morir desasido de ellos y de todo amor propio y pido a su Divina Majestad renueva y aparte de mi corazón todo afecto temporal para que viva y muera asido sólo a su amor», lo expresaría D. Francisco Fonseca y Gamis: APNCO, 11, p. 133 (1780), 97-106r., f $97 \mathrm{v}$.

46. Nieremberg, J. E., Obras christicnas del..., pp. 678-705. Fernández, A., Instrucción de..., $2^{a}$ parte, ff. 7-46 y 48-51. Venegas, A., Agonía del..., pp. 52-4. García, P., Sermones panegíricos..., III, 62-103. Instrucciones de San Carlos..., pp. 255-260 y 271-4. Mach, J., Tesoro del..., 2, p. 456. Montañes, J., Espejo de bien..., pp. 105, 330-1, 334-5, 350 y 394.

47. Chevassu, Mr., Misionero parroquial..., pp. 210-2.

48. Groethuysen, B., La formación de la..., p. 89, ns. 16-7, p. 460.

49. Ligorio, A. Ma de, Preparación para la..., p. 18.

50. Montañés, J., Espejo de bien..., p. 206. Mitre, E., La muerte..., p. 71. Thomas, L. v., El cadáver. De la..., pp. 13-4, 19-27.

51. «De un aspecto alegremente serio, y al tacto flexible [...], nada alterado, y de color de rosa seca, y sus manos, cuello y pies, con la misma flexibilidad», era el semblante que presentaba la persona que hubiese sufrido una buena muerte, una muerte santa, tranquila, ejemplar, ejemplarizante y edificante para la comunidad, $y$, como resultado final de una buena vida, esto es importante, verdaderamente cristiana: fue talmente la que tuvo, y lo que a su cadáver ocurrió y del que se dijo, $D^{a}$ María Mexía y Morillo, natural de Granada y conocida popularmente en Córdoba como. «la hermana María»: Archivo Parroquial de San Andrés, tomo 10, Libro de Entierros desde el 9 de Enero de 1751 a 24 de Noviembre de 1778 , ff. $99 \mathrm{v}-100 \mathrm{r}$.

52. En suma -y siendo por violencia o pecado, señal también de muerte horrible (Martínez Gil, F., Muerte y..., pp. 140-9), y como incluso literariamente se ha recreado-, la misma muerte, «vestida de negro $y$ más fea que un voto a Dios; era más amarilla y más descarnada que un pergamino de Simancas; tenía los ojos hundidos y amortecidos como candil sin aceite; la boca como una espuerta; en cuanto a nariz, aquí estuvo: no habia nada, ni memoria, perdone usted por Dios»: Fernán Caballero, «Juan Holgado y la...», p. 106. 
y libertador del alma que es llevada o entregada a Dios ${ }^{53}$-se inicia ahora el juicio individual-: en silencio, ojos y boca cerrados pues, ocurrido y constatado el fallecimiento, es lo primero que hace el pariente más allegado o la persona más próxima al difunto para significar así que los sentidos corporales han muerto para el mundo y se han abierto los del alma ${ }^{54}, \mathrm{y}$, de momento solo, el difunto queda ya, en su habitación y para su decente preparación, a disposición de la intimidad familiar.

\section{CONSIDERACIONES FINALES}

1. Hemos estudiado el «rito de separación»-rito estrecho donde los haya- de la agonía en el genérico rito de paso que es la misma muerte ${ }^{55}$.

2. También dado a conocer ese momento tan especial y sin retorno de la muerte desde el documento de última voluntad, y hacerlo específicamente desde el formulario testamentario -por lo demás, el canal más adecuado-, buscando recrear su riqueza y detalle. Aquella huella ha sido poco utilizada e incluso criticada por su escasa locuacidad y permeabilidad sobre este punto. En este sentido, es cierto que, como para otros aspectos del ritual, quizás también para éste no sea el documento más idóneo por la rareza de las declaraciones sobre este asunto, probablemente por afectar a lo íntimo o lo sabido y, por tanto, no necesitado de explicitación; pero esto no significa que no existan y lo traten. Antes al contrario, hemos comprobado que sí, y de forma incluso prolija en algunos momentos, y, por tanto, que es posible el análisis de la agonía a su través.

Por lo demás, ésta no se muestra sensible a los elementos diferenciales y, por ende, se mantiene más allá de las condiciones sexuales y socioeconómicas, y a lo largo del espacio y el tiempo, como se ha podido ver.

3. Igualmente hemos mostrado cómo en la agonía se manifiesta magníficamente la simbiótica y perfecta combinación de privacidad-publicidad de la muerte preindustrial.

4. También ante este tema, y una vez más, existencia de la disparidad idealidad/realidad pues, estudiando la agonía, se observa que se cumple a medias el ideal eclesiástico de buena muerte. Éste prescribía, y por este preciso y riguroso orden, testamento en salud, recepción de últimos sacramentos y agonía asistida. El orden ritual real -es decir, social, vivido- entregaba, también por este preciso y riguroso orden, recepción de los últimos sacramentos, testamento -y éste en mayoritario estado de enfermedad- y agonía, asistida si había tiempo y medios.

La documentación examinada no sólo demuestra la disfunción antedicha, sino también que la misma Iglesia aceptaba definitivamente la realidad, pero a cambio de anteponer al cuerpo el alma; de ahí, y como específicamente expresan los propios interesados y protagonistas $-«[\ldots]$ habiendo hecho las diligencias que como cristiano debo, de haber recibido los santos sacramentos de la penitencia, eucaristía y extre-

53. Producida al fin la muerte, ese «apartamiento del cuerpo y del alma», esa «privación con que se acaba la vida mortal» (Venegas, A., Agonía del..., p. 19), esa «ruptura entre cuerpo y alma» (Vicastillo, S., Tertuliano y la..., p. 65), que origina la salida de ésta, todavía, sin embargo, hay que seguir, con oraciones y responsos, rezando: Fernández, A., Instrucción de..., pp. 46-8.

54. Martínez Gil, F., Muerte y..., p. 392.

55. Gennep, A. v., Los ritos de..., pp. 158-177. 
maunción, quiero declarar mi última voluntad [...]" ${ }^{56}$; "he podido confesar y recibir los santos sacramentos, $y$ ahora quiero otorgar mi testamento ${ }^{57}-$, que precedan Ios últimos sacramentos al testamento, y que se imponga el espíritu a la materia.

5. Por último -y como asimismo hemos visto-, transcurrida la agonía, lo que queda es la muerte - «hallé al susodicho [el difunto] tendido sobre un tabladillo, cubierto de bayeta negra, amortajado con hábito de los religiosos franciscos y dos velas de cera alumbrando una santa cruz, y por el semblante que tenía, llanto y congoja de su mujer e hijos y demás demostraciones de sentimiento que advertía, no quedaba duda estar el referido cadáver ${ }^{58}-$, comenzando a poco otra historia distinta de la que aquí nos ha ocupado.

\section{BIBLIOGRAFÍA UTILIZADA}

BIBLIA de Jerusalén. Edición española preparada y dirigida por J. A. Ubieta, Madrid, 1972², 2.088 .

BOSCH DE CENTELLAS Y CARDONA, B., Prácticas de visitar los enfermos y ayudar a bien morir, Valladolid, $1847^{2}, 352$.

COSTUMBRISMO Romántico, El. Selección de Mesonero Romanos, Estébanez Calderón, Eugenio de Ochoa, Duque de Rivas y Larra. Introducción, notas y selección de J. L. Varela, Madrid, 1970, 167.

CHEVASSU, Mr., Misionero parroquial ó Sermones para todos los domingos del año, III, Madrid, 1797.

ELIADE, M., Lo sagrado y lo profano, Madrid, 1973, 185.

FERNÁN CABALLERO, «Juan Holgado y la muerte», en Obras Completas, Madrid, BAE, V, 1961.

FERNÁNDEZ, A., Instrucción de enfermeros, y modo de aplicar los remedios, a todo género de enfermedades, y acudir a los accidentes, que sobrevienen en ausencia de los médicos. Contiene asimismo: Tratado de lo que se ha de hazer con los que están en el articulo de la muerte, sacado de diversos Libros Espirituales, Madrid, 1728, 152 y 52.

GARCÍA, P. M. R., Sermones panegíricos de varios misterios, festividades y santos, III, Madrid, 1805.

GARZÓN, F. de P., Devocionario en honor del Patriarca San José, Madrid, 1911, 125.

GENNEP. A. v., Los Ritos de Paso, Madrid, 1986, 215.

GONZÁLEZ CRUZ, D., Religiosidad y ritual de la muerte en la Huelva del Siglo de la Ilustración, Huelva, 1993, 589.

GROETHUYSEN, B., La formación de la conciencia burguesa en Francia durante el siglo XVIII, Madrid, 1981, 647.

HILDEBRAND, D. v., Sobre la muerte, Madrid, 1983, 156.

INSTRUCCIONES de San Carlos Borromeo sobre la administración del Sacramento de la Penitencia, con los cánones penitenciales y Pastoral del Ilmo. Sr. D. Antonio de Godeau,

56. APNCO, 15, p. 102 (1750), 23-26v., fo 23r.: Testamento. de Andrés Martín Bermejo.

57. APNCO, 7, p. 121 (1730), 69-70v., f 69r.: Testamento de D. Francisco Bélez de Escalante.

58. APNCO, 27, p. $123(1830), 214-271 \mathrm{v}$., f $215 \mathrm{v}$.: Inventario a los bienes que dejó por su fallecimiento Antonio Gómez. 
Obispo de Vence, en que les dirige a su clero, traducidas del latín e italiano por F. Lázaro de Hortal, Madrid, 1782, 340.

LACORDAIRE, E. D., Sermones predicados en la iglesia de Nuestra Señora de Paris, predicados por el Rvdo. Padre..., I, París, s. a.

LIGORIO, A. Ma de, Preparación para la muerte ó consideraciones sobre las verdades eternas, útiles a los fieles para meditar, y a los sacerdotes para el púlpito, Barcelona, $1881^{\text {, }}$ 573.

MACH, J., Tesoro del sacerdote ó repertorio de las principales cosas que ha de saber y practicar el sacerdote para santificarse a sí mismo y a los demás, II, Barcelona, 1907":, 925.

MARTÍNEZ GIL, F., Muerte y sociedad en la España de los Austrias, Madrid, 1993, 700.

MITRE FERNÁNDEZ, E., La muerte vencida. Imágenes e historia en el Occidente Medieval (1200-1348), Madrid, 1988, 150.

MONTAÑÉS, J., Espejo de bien vivir y para ayudar a bien morir, Madrid, 1976, 410. [La obra príncipe se imprimió en Valencia en 1559, dividida en dos partes: una dedicada al «bien vivir», y la segunda al «bien morir»; al principio de la segunda parte, el autor introdujo la traducción íntegra de los once capítulos del conocido tratado medieval «Ars Moriendi». En castellano se imprimió la obra en Madrid en 1573. Se ha adjudicado asimismo al autor otro segundo tratadito llamado «Espejo y arte de bien morir», publicado por primera vez en Valencia en 1565. Se trata, en realidad, de una refundición completa de la segunda parte de la anterior obra, y se acompaña de una meditación sobre la Pasión y Muerte de Cristo].

NICOLAS, J. et R., La vie quotidienne en Savoie aux XVIle et XVIIIe siècles, Biarritz, 1979, 380.

NIEREMBERG, J. E., Obras Christianas. Que contienen lo que debe el hombre hazer para vivir, y morir christianamente, temiendo á Dios, despreciando el mundo, estimando la gracia, entendiendo la Doctrina Christiana, y preparandose para la muerte, I, Sevilla, 1686, 752.

ROYER DE CARDINAL, S., Morir en España (Castilla Baja Edad Media), Buenos Aires, s. a. [circa 1990], 353.

THOMAS, L. v., El cadáver. De la biología a la antropología, Méjico, 1989, 196.

VENEGAS, A., Agonía del tránsito de la muerte, con los avisos, y consuelos, que acerca della son provechosos, Barcelona, 1682, 329.

VICASTILLO, S., Tertuliano y la muerte del hombre, Madrid, 1980, 338.

VOVELLE, M., Piété baroque et déchristianisation en Provence au XVIIIe siècle, París, 1978 , 346.

ZORITA, A., Catecismo del Santo Concilio de Trento para los párrocos, ordenado por disposición de San Pio V, I-II, Barcelona, 1807 [Primera edición, Roma, 1761]. 